\title{
One year of CNR-IMAA multi-wavelength Raman lidar measurements in coincidence with CALIPSO overpasses: Level 1 products comparison
}

\author{
L. Mona, G. Pappalardo, A. Amodeo, G. D’Amico, F. Madonna, A. Boselli, A. Giunta, F. Russo, and V. Cuomo \\ Consiglio Nazionale delle Ricerche - Istituto di Metodologie per l'Analisi Ambientale (CNR-IMAA), C. da S. Loja, \\ 85050 Tito Scalo, Potenza, Italy
}

Received: 19 January 2009 - Published in Atmos. Chem. Phys. Discuss.: 31 March 2009

Revised: 29 August 2009 - Accepted: 4 September 2009 - Published: 29 September 2009

\begin{abstract}
At CNR-IMAA, an aerosol lidar system has operated since May 2000 in the framework of EARLINET (European Aerosol Research Lidar Network), the first lidar network for tropospheric aerosol study on a continental scale. High quality multi-wavelength measurements make this system a reference point for the validation of data products provided by CALIPSO (Cloud-Aerosol Lidar and Infrared Pathfinder Satellite Observations), the first satellite-borne lidar specifically designed for aerosol and cloud study. Since 14 June 2006, dedicated measurements have been performed at CNR-IMAA in coincidence with CALIPSO overpasses. For the first time, results on 1-year comparisons between ground-based multi-wavelength Raman lidar measurements and corresponding CALIPSO lidar Level 1 profiles are presented. A methodology for the comparison is presented and discussed in detail. Night-time cases are considered to take advantage from Raman capability of the ground based lidar. Cases with the detection of cirrus clouds in CALIPSO data are separately analysed for taking into account multiple scattering effects. For cirrus cloud cases, few cases are available to draw any conclusions. For clear sky conditions, the comparison shows good performances of the CALIPSO on-board lidar: the mean relative difference between the ground-based and CALIPSO Level 1 measurements is always within its standard deviation at all altitudes, with a mean difference in the $3-8 \mathrm{~km}$ altitude range of $(-2 \pm 12) \%$. At altitude ranges corresponding to the typical PBL height observed at CNRIMAA, a mean difference of $(-24 \pm 20) \%$ is observed in
\end{abstract}

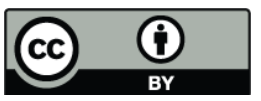

Correspondence to: L. Mona

(mona@imaa.cnr.it)
CALIPSO data, probably due to the difference in the aerosol content at the location of PEARL and CALIPSO groundtrack location. Finally, the mean differences are on average lower at all altitude ranges for the closest overpasses (at about $40 \mathrm{~km}$ ) respect to the $80-\mathrm{km}$ overpasses.

\section{Introduction}

Tropospheric aerosols, and in particular anthropogenic aerosols, are one of the most uncertain elements in the estimation of radiation budget. In fact, the uncertainties in aerosol direct and indirect anthropogenic forcing are of the same magnitude of the effects themselves (Forster et al., 2007). The main cause of uncertainty is the large tropospheric aerosol variability in space and time. It is well known that a coordinated approach of local, regional, and global observations, and physical, chemical, radiation, and dynamics modelling is needed for dramatically improving our understanding of aerosol climate impacts and environmental interactions (Diner et al., 2004). In addition, it has to be considered that in the past, the variability of the horizontal and temporal distribution of aerosols and of their optical properties has been investigated mainly by means of passive remote sensing instruments on board of satellites or ground based sun photometers networks like AERONET (Kaufmann et al., 2000; Anderson et al., 2003; Omar et al., 2005; Kahn et al., 2007). In these studies based on columnar measurements, there is no information about the vertical distribution of the aerosols that is a crucial point for the aerosol-clouds interaction study. Moreover, since vertical concentration gradients can lead also to significant horizontal inhomogeneities, the

Published by Copernicus Publications on behalf of the European Geosciences Union. 
lack of information about the vertical mixing can be a large source of variability typically neglected in the models.

Aerosol profiling with high resolution both in time and space provided by lidar techniques is an indispensable tool to study the vertical structure of aerosol field and its temporal and spatial evolution. Moreover, lidar techniques can penetrate optically thin clouds allowing, therefore, the aerosolclouds interactions and aerosol indirect effects on the radiation budget to be investigated.

Since mid June 2006, CALIPSO (Cloud-Aerosol Lidar and Infrared Pathfinder Satellite Observations), the first satellite-borne lidar specifically designed for aerosol and cloud study, has provided high vertical resolution profiling of aerosol and clouds on global scales (Winker et al., 2007). Flying in the A-train constellation, CALIPSO offers, for the first time, the possibility for developing an integrated strategy between lidar and passive remote sensing techniques thanks to the synergies among different A-train sensors for studying both aerosols and clouds (Stephens et al., 2002; Anderson et al., 2005; Hu et al., 2007; Lamquin et al., 2008; Sassen et al., 2008).

CALIOP (Cloud-Aerosol Lidar with Orthogonal Polarization), the lidar on board CALIPSO, is an elastic backscatter lidar that provides vertical profiles of aerosol and cloud backscatter coefficients at $532 \mathrm{~nm}$ and $1064 \mathrm{~nm}$ and depolarization ratio profiles at $532 \mathrm{~nm}$. Since the equation for a lidar in the elastic configuration has two unknowns, the extinction and backscatter coefficients, an assumption on their ratio, i.e. the lidar ratio, is needed for retrieving profiles of extinction and backscatter coefficients from the CALIOP measurements. A first guess of the lidar ratio is selected in the CALIPSO retrieval algorithms according to the type and subtype of the layer being analysed and mainly on the base of AERONET climatological studies and model calculations (Cattrall et al., 2005; Liu et al., 2005; Young et al., 2008). However, it has been observed that even for the same kind of aerosol, the lidar ratio can vary widely because of the natural variability of each aerosol species and of the aerosol modification/transportation processes (Mona et al., 2006; Müller et al., 2007, 2009; Papayannis et al., 2008). In order to increase and validate the accuracy of aerosol optical properties retrieved from the CALIPSO pure backscatter lidar, comparisons with ground-based elastic/Raman lidar and/or High Spectral Resolution Lidar (HSRL) measurements are strongly necessary, since these techniques allow the characterization of atmospheric aerosols in terms of vertical profiles of extinction and backscatter coefficients without any assumptions on the aerosol type and composition (Ansmann et al., 1990, 1992; Hair et al., 2008). However, before proceeding with the comparison of final CALIPSO products (namely the Level 2 products), it is important to study and assess the accuracy of CALIPSO raw signals (Level 1 data). This is essential to identify, if it is the case, the contribution of specular reflection and multiple scattering effects, and possible biases due, for example, to low accuracy at some altitude ranges because of low SNR and to the calibration procedure. Only after a check of the unprocessed CALIPSO data, the comparison in terms of Level 2 products will allow one to check and improve CALIPSO retrieval algorithms and assumptions. By, first of all, comparing our ground-based measurements with the CALIPSO Level 1 data products, we can distinguish any potential problems and biases already contained in the calibrated CALIPSO lidar signals from any errors and uncertainties that might result from any invalid assumptions or approximations used in the optical properties retrieval algorithms. As shown in the present work, a comparison in terms of CALIPSO Level 1 data from groundbased measurements is possible without assumptions only if independent extinction and backscatter profiles are available, as is possible with the elastic/Raman technique.

In this paper, the methodology for addressing this kind of comparison is presented and discussed in detail, and, for the first time, a 1-year comparison between ground-based multiwavelength Raman lidar measurements and corresponding CALIPSO lidar profiles is presented. After a brief description of the CNR-IMAA multi-wavelength lidar system operational within EARLINET (Bösenberg et al., 2000), the methodology for the comparison in terms of CALIPSO Level 1 data is presented. In particular, the status of the correlative measurements acquired at CNR-IMAA since June 2006 following the EARLINET devoted strategy for CALIPSO measurements (Mattis et al., 2007) is presented. Then the procedure for the calculation of profiles to be compared to CALIPSO Level 1 profiles from aerosol extinction and backscatter profiles measured by means of the CNR-IMAA lidar is presented and discussed. In the third section a comparison for a strong Saharan dust event is reported as example of the applied methodology. Then results on 1-year of nighttime measurements are reported for cirrus cloud cases and clear sky conditions. Finally, conclusions and perspectives are given.

\section{Elastic/Raman aerosol lidar system}

At the CNR-IMAA, located in Tito Scalo, Potenza $\left(40^{\circ} 36^{\prime} \mathrm{N}\right.$, $15^{\circ} 44^{\prime} \mathrm{E}, 760 \mathrm{~m}$ above sea level), a Raman lidar system for tropospheric aerosol study has been operational since the beginning of EARLINET in May 2000. The Potenza EARLINET lidar (PEARL) is based on a Nd:YAG laser equipped with second and third harmonics generators and on a Cassegrain reflecting telescope with a primary mirror of $500 \mathrm{~mm}$ diameter and combined focal length of $5 \mathrm{~m}$. The three laser beams at 1064, 532 and $355 \mathrm{~nm}$ are simultaneously and coaxially transmitted into atmosphere after they are separately expanded. The receiving system has 3 channels for the detection of the radiation elastically backscattered from the atmosphere at the 3 laser wavelengths and two channels for the detection of the Raman radiation backscattered from the atmospheric N2 molecules at 607 and $386 \mathrm{~nm}$. 
An additional Raman channel at $407 \mathrm{~nm}$ collects radiation backscattered from the water vapor molecules present in the atmosphere. Finally a cubic polarizing beam splitter allows the detection of components of backscattered light polarized perpendicular and parallel to the direction of the linearly polarized transmitted laser beam. The backscattered radiation collected by the telescope is spectrally selected by means of dichroic mirrors and interference filters with a bandwidth of $0.5 \mathrm{~nm}$. After spectral selection, the signal at each wavelength is furthermore split in two signals of different intensity by means of a beam splitter. This allows a lidar signal extending from low altitude to the free troposphere to be obtained with a good signal counting statistics while not exceeding the limits of the counting scale.

PEARL allows independent measurements of the aerosol extinction and backscatter coefficients, and therefore of the lidar ratio at $532 \mathrm{~nm}$ and $355 \mathrm{~nm}$, thanks to the combined elastic/Raman approach (Ansmann et al., 1990; Ferrare et al., 1998). An iterative approach (Di Girolamo et al., 1999) is used for retrieving the aerosol backscatter coefficient at $1064 \mathrm{~nm}$ from the elastically backscattered lidar signal at this wavelength and assuming a lidar ratio profile at $1064 \mathrm{~nm}$, on the basis of literature values and simultaneous lidar ratio measurements at 532 and $355 \mathrm{~nm}$.

With this lidar system, it is possible to measure vertical profiles of aerosol optical properties from the low troposphere to the upper troposphere. The full overlap between the transmitted laser beam and the telescope field of view for this system is reached at about $0.8 \mathrm{~km}$ above the lidar station. However, the elastic/Raman method for the determination of the aerosol backscatter coefficient profile at 355 and $532 \mathrm{~nm}$ involves the ratio of two lidar signals, therefore the overlap effect is partially corrected and these profiles typically start from $400 \mathrm{~m}$ above the ground. For the other products, a correction for the incomplete overlap (Wandinger and Ansmann, 2002 ) is applied and this allows the determination of profiles of the aerosol extinction coefficient at $532 \mathrm{~nm}$ and $355 \mathrm{~nm}$ and of the aerosol backscatter coefficient at $1064 \mathrm{~nm}$ that typically start from $500 \mathrm{~m}$ above the lidar station.

Aerosol optical properties vertical profiles are typically obtained by $30 \mathrm{~min}$ of temporal integration of the signals, and with an effective vertical resolution of $60 \mathrm{~m}$ for the aerosol backscatter coefficient and ranging between 60 and $240 \mathrm{~m}$ for the aerosol extinction coefficient and lidar ratio. In cases of high temporal variability shown by the PEARL acquired range corrected signal, a shorter temporal window for optical properties retrieval allows the reduction of systematic errors due to variability in aerosol and cloud fields (Ansmann et al., 1992). With these resolutions, in night time conditions, typical statistical errors due to the signals detection in the PBL are below $5 \%$ for the aerosol backscatter coefficients at 355 and $532 \mathrm{~nm}$, and below $10 \%$ for the extinction coefficients at $355 \mathrm{~nm}$ and $532 \mathrm{~nm}$. In the free troposphere, typical statistical errors are below $30 \%$ for aerosol backscatter at 355 and $532 \mathrm{~nm}$ and aerosol extinction, for values of the aerosol extinction at $532 \mathrm{~nm}$ higher than about $0.03 \mathrm{~km}^{-1}$. Both the system and the algorithms used have been quality checked and are the object of continuous checks within the EARLINET Quality Assurance program (Matthias et al., 2004; Böckmann et al., 2004; Pappalardo et al., 2004; Amodeo et al., 2007).

\section{PEARL vs. CALIPSO comparison methodology}

\subsection{Measurements strategy}

Because of its Raman multi-wavelength capability, PEARL is a high-quality reference point for CALIPSO measurements of the aerosol backscatter coefficient at 532 and $1064 \mathrm{~nm}$. In particular, the PEARL simultaneous measurements of aerosol extinction and backscatter profiles at $532 \mathrm{~nm}$ allow the estimation of the errors on the CALIPSO backscatter profiles due to lidar ratio assumptions and therefore to improve the algorithms for these retrievals. Furthermore, PEARL aerosol extinction and backscatter measurements at $355 \mathrm{~nm}$, and water vapor mixing ratio profiles, add useful information about microphysical aerosol properties that can be used to improve the retrieval of aerosol backscatter coefficient from pure backscatter lidar.

Since 14 June 2006, devoted measurements have been performed at CNR-IMAA in coincidence with CALIPSO overpasses according to the CALIPSO Science Team requests for the validation purposes. Measurements are performed each time that CALIPSO overpasses PEARL's location within a maximum distance of $100 \mathrm{~km}$ and 2 hours. Additional measurements are performed in agreement with EARLINET specific strategy designed for the CALIPSO measurements (Mattis et al., 2007). The network measurements plan is distributed to all stations once per week, including, for each station, measurements with CALIPSO overpass within $100 \mathrm{~km}$ (Case1) and additional measurements when the EARLINET closest station and the multi-wavelength EARLINET closest station perform measurements in coincidence with CALIPSO (respectively Case2 and Case3). This kind of measurement was suggested for exploiting the EARLINET network's capability to investigate the modification of aerosol properties over the European continent and for combining all these information with CALIPSO profiles. In the following, only Case 1 measurements will be considered because these measurements allow the point-to-point comparison between ground-based and satellite-borne lidar measurements, that is the aim of the current paper.

Following this strategy of measurements, 68 measurements were performed at CNR-IMAA as Case 1 in the June 2006-June 2007 period, covering 77\% of the Case 1 measurements scheduled for our station. For these measurements the average minimum distance between PEARL and CALIPSO is $66.5 \mathrm{~km}$, reaching an absolute minimum distance of $40.3 \mathrm{~km}$. Figure 1 reports two examples of 


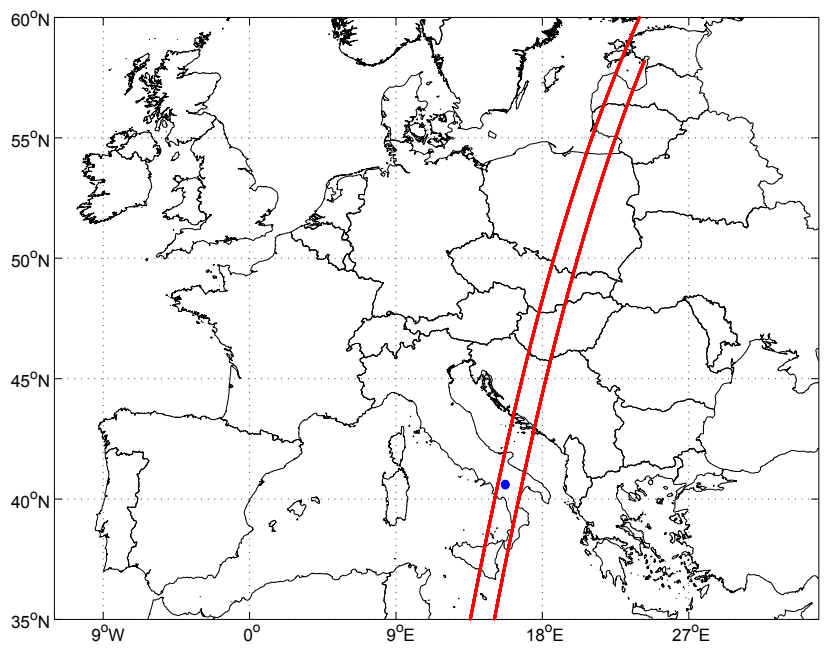

Fig. 1. PEARL location (blue dot) and typical CALIPSO night-time orbits overpassing Potenza (red lines).

night-time CALIPSO overpasses over Potenza, examples representative of the 2 typical overpasses with a minimum distance of about 40 and $80 \mathrm{~km}$.

\subsection{Attenuated backscatter comparison}

Ground-based lidars at $3+2$ wavelengths are an optimal tool for validation of CALIPSO products, because they provide independent measurements of the particulate backscatter and extinction at $532 \mathrm{~nm}$ and backscatter at $1064 \mathrm{~nm}$ profiles that can be directly compared to analogous quantities derived from CALIPSO. However, before these comparisons can be made, it is necessary to assess the quality of CALIPSO Level 1 data in order to distinguish problems and possible biases contained in the acquired lidar signal from uncertainties and errors related to the Level 2 retrieval algorithms.

The main product contained in the CALIPSO Level 1 data is the attenuated backscatter profile, i.e. its range-corrected lidar signal expect for a calibration constant (Hostetler et al., 2006).

The attenuated backscatter coefficient $\beta^{\prime}$ provided by CALIPSO is defined at each altitude $z$ as (Hostetler et al., 2006):

$\beta^{\prime}(z)=\beta_{\mathrm{tot}}(z) T_{\mathrm{par}}^{2}(z) T_{\mathrm{mol}}^{2}(z) T_{\mathrm{O}_{3}}^{2}(z)$

where $\beta_{\text {tot }}$ is the backscatter coefficient resulting from particles, molecular and ozone contributions:

$\beta_{\mathrm{tot}}(z)=\beta_{\mathrm{par}}(z)+\beta_{\mathrm{mol}}(z)+\beta_{\mathrm{O}_{3}}(z)$

and $T_{\text {par }}^{2}(z), T_{\text {mol }}^{2}(z)$ and $T_{\mathrm{O}_{3}}^{2}(z)$ are the transmittance terms present in the elastic lidar equation due respectively to the particles, molecules and ozone contained in the atmosphere layer extending between the lidar and the altitude $z$.
The attenuated backscatter profiles provided by CALIPSO are not directly comparable to PEARL profiles, so a procedure has to be followed in order to compare PEARL and CALIPSO independent measurements. In retrieving attenuated backscatter profiles from PEARL data, it has to be taken into account that PEARL and CALIPSO transmittance terms are different, because the first lidar is an upward looking lidar and CALIPSO is a downward looking lidar. The molecular terms in (1), both backscatter coefficient and transmittance, can be obtained by a collocated radiosounding if available or can be well approximated using a modelled atmosphere. The ozone terms can be estimated from ozone profiles available directly as meteorological data embedded in CALIPSO Level 1 products and taking into account the ozone absorption at $532 \mathrm{~nm}$ in the Chappuis band (Brasseur and Solomon, 1985).

The particulate backscatter coefficient in (1) is measured by upward-looking PEARL system. The particulate transmittance term can be calculated from PEARL measurements using the independent measurements of particulate extinction profiles. In fact, the particulate transmittance term for a downward-looking lidar can be written as function of the particulate extinction:

$T_{\mathrm{par}}^{2}(z)=\exp \left(-2 \int_{z}^{z_{s}} \alpha_{\mathrm{par}}(\zeta) d \zeta\right)$

where $z_{s}$ indicates the satellite-borne lidar altitude (Hostetler et al., 2006).

Therefore, from simultaneous and independent measurements of aerosol backscatter and extinction profiles measured by PEARL, it is possible to calculate the CALIPSOlike attenuated backscatter (CLAB) profile at $532 \mathrm{~nm}$ without any significant assumptions.

In the comparison between satellite and ground-based lidar signals, the multiple scattering effects should be taken into account. For cirrus clouds cases, a cirrus-clearing procedure, described in Sect. 5.1, allows us to remove multiple scattering effects and therefore a quantitative comparison between satellite and ground-based signals is possible. In absence of cirrus clouds, the multiple scattering contribution to the ground-based lidar signals is negligible (Ansmann et al., 1992b). For CALIPSO data, multiple scattering effects can be non-negligible, especially in case of large quantities of aerosol lofted in the atmosphere. In these cases, the comparison with the CALIPSO-like attenuated backscatter calculated by independent ground-based measurements can allow the evaluation of the multiple scattering effect.

\subsubsection{The molecular profile}

As reported above, PEARL measurements allow the calculation of the CALIPSO-like attenuated backscatter if the ozone and molecular terms in the Eq. (1) are calculated from radiosoundings or models. In this paragraph we deal explicitly 


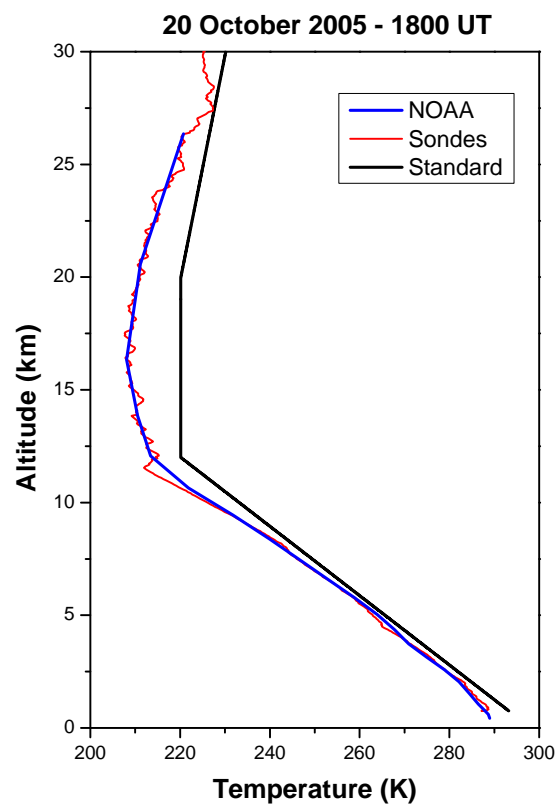

Fig. 2. Temperature profile measured by balloon-borne radiosounding system launched at CNR-IMAA on 20 October 2005, 18:00 UTC (red line). The corresponding US standard atmosphere profile and the NOAA model profiles are reported as black and blue lines, respectively.

with the calculation of these molecular terms and their influences on the retrieved CLAB uncertainties.

The ozone term contribution on the CLAB calculation is less than $0.5 \%$ below $10 \mathrm{~km}$ and within $3 \%$ above. Considering that the changes in the tropospheric ozone will not affect significantly the CLAB calculation and that the stratospheric ozone is not highly variable, differences due to the ozone profile used for the CLAB calculation can be considered negligible. In the following, for each attenuated backscatter profile comparison, the corresponding ozone profile available directly as meteorological data embedded in CALIPSO Level 1 products is used.

More relevant is the contribution of the molecular terms in (1) that can be exactly calculated if vertical temperature and pressure are known, using Bucholtz's approach (Bucholtz, 1995). This method requires as input the vertical profiles of pressure and temperature. For our purposes, simultaneous and lidar collocated measurements of these quantities, for example with radiosoundings, would be obviously the best solution. However, this is not always possible, also because of the expensive cost of radiosondes launch and of the sparse temporal sampling of these measurements. Therefore, alternative solutions have to be explored. The most common way to proceed is to use US standard atmosphere profiles (US Standard Atmosphere, 1976). These profiles are typically used in a satisfactory way also for the calculation of the density profiles needed for the aerosol backscatter and extinction

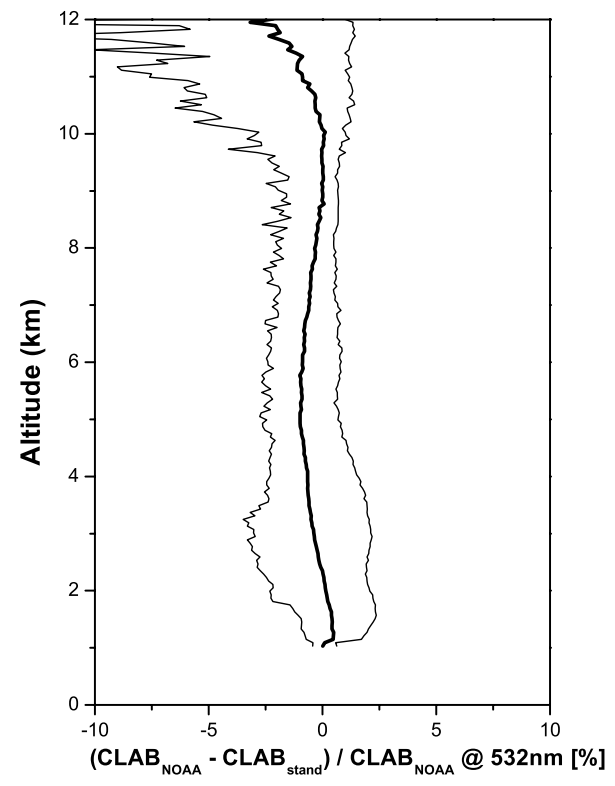

Fig. 3. Difference in CALIPSO-like attenuated backscatter (CLAB) resulting from the use of NOAA model profile instead of using US atmosphere standard profile. The thick line reports the mean profile calculated over all the selected cases for CALIPSO - PEARL comparison, the thin lines report the minimum and maximum observed differences in CLAB profiles.

retrieval from lidar measurements (see for example Ansmann et al., 1990, 1992).

Significant differences can be observed, especially in the temperature, between the true atmospheric profile and the corresponding standard atmosphere one. This is evident in Fig. 2, where temperature profile as measured with a radiosonde launched at CNR-IMAA on 20 October 2005, 18:00 UTC and the corresponding standard atmosphere profile are reported. In the troposphere differences up to $3-4 \mathrm{~K}$ are observed and a difference of about $10 \mathrm{~K}$ is observed in the $15-20 \mathrm{~km}$ altitude range.

A better estimation of the temperature profile is provided by NOAA model profiles available at www.arl.noaa.gov, where meteorological products for any location in the world are provided through the GDAS (Global Data Assimilation System) operational system run by NCEP (NOAA National Centers for Environmental Prediction). Figure 2 shows a very good agreement between NOAA modelled radiosounding temperature profile and the true state of the atmosphere measured by CNR-IMAA radiosounding. The vertical resolution of this modeled radiosounding is obviously higher and temperature gradients like that observed on 20 October 2005 at about $11.5 \mathrm{~km}$ a.s.l. cannot be caught by NOAA model.

A systematic comparison between radiosondes and NOAA modelled temperature vertical profiles has been carried out using all available CNR-IMAA radiosounding profiles for 2005 (68 cases). The mean difference is very close to zero 

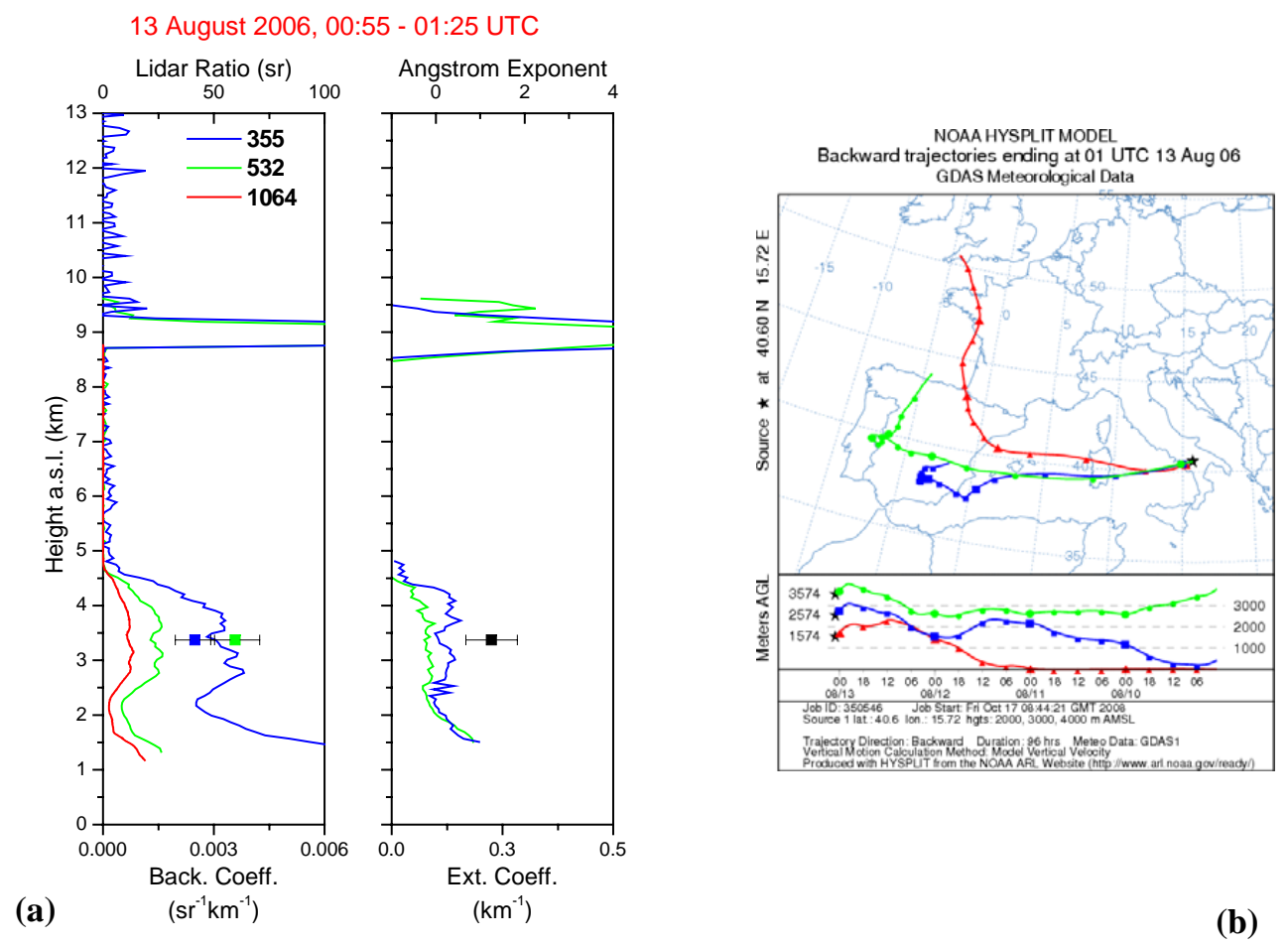

Fig. 4. Vertical profiles of backscatter and extinction as measured by PEARL on 13 August 2006, 00:55-01:25 UTC (a). Scattered points report the mean values of lidar ratio and Angstrom exponent measured in the free troposphere aerosol layer $(2.4-4.3 \mathrm{~km})$. One standard deviation is reported for these mean values as error bar. NOAA Hysplit back-trajectory analysis for 13 August 2006, 01:00 UTC (b).

$(0.03 \pm 0.07 \mathrm{~K})$ and lower than $0.2 \mathrm{~K}$ in the $0-10 \mathrm{~km}$ altitude range. In addition, the profile-to-profile difference never exceeds $2.5 \mathrm{~K}$ in the $0-10 \mathrm{~km}$ range. On the basis of this analysis, we can affirm that if radiosounding data are not available, NOAA modelled profiles are preferred to the simple standard atmosphere profiles. At this point, it is interesting to quantify how large is the influence of this choice on the attenuated backscatter as retrieved from a ground-based lidar.

For the period June 2006-June 2007, no CNR-IMAA radiosounding profiles are available, therefore we limit the comparison to the NOAA modelled radiosounding and the US standard atmosphere model. For all considered cases, the CALIPSO-like attenuated backscatter at $532 \mathrm{~nm}$ is calculated from the aerosol extinction and backscatter profiles measured by PEARL using the NOAA modelled temperature and pressure profiles and the US standard atmosphere profiles for the calculation of the molecular terms in (1). Then, for each case, the difference between the CLAB profiles obtained with the two different modelled atmosphere profiles is calculated. The mean CLAB difference profile, in percentage, is reported in Fig. 3 as thick line. On the whole profile, the mean difference is on average of about $-1 \%$, with lowest values below $4 \mathrm{~km}$ a.s.l. (lower than $0.5 \%$ in absolute value) and however lower than $\pm 1 \%$ up to $11 \mathrm{~km}$ a.s.l.. Larger values are observed for higher altitudes where the aerosol contribution is typically negligible and therefore the molecular terms prevail. However, the difference in CLAB due to the modelled atmosphere is lower than $2.5 \%$ on average also at altitude of about $12 \mathrm{~km}$ staying however below the statistical error, typically of about $20 \%$, of PEARL ground-based CLAB profiles at this altitude. The minimum and maximum observed differences in CLAB profiles are reported as thin lines in Fig. 3, together with mean difference profile. Even in the worst cases the influence of modelled atmospheric temperature and pressure profile choice is well below $5 \%$ up to $10 \mathrm{~km}$, reaching the highest values of $10 \%$ only at $11-12 \mathrm{~km}$.

Our analysis allows us to affirm that, if radiosonde profiles are not available, the NOAA modelled profiles have to be preferred to the standard atmosphere profiles, but that for a statistical analysis in terms of attenuated backscatter comparison with CALIPSO data the influence of the chosen atmosphere description is negligible (typically below $1 \%$ ). In cases of single profile comparison instead, the differences can be larger especially above $10 \mathrm{~km}$ a.s.l., therefore for this kind of investigation the assumption about atmospheric density profile is more critical for the calculation of the molecular terms in (1). In the following, NOAA modelled radiosounding data are used, because of their better performances with respect to the standard atmospheric profiles.

Retrieved CLAB profiles are affected by both statistical and systematic errors, resulting from backscatter and extinction error propagation and from the use of ozone profile 
available in CALIPSO Level 1 products and of NOAA modelled radiosounding data. Errors resulting from extinction coefficient error, both statistical and systematic, are negligible, because extinction is involved in the CLAB calculation through the transmittance term. Systematic errors on aerosol backscatter with elastic Raman techniques are almost negligible, and moreover, less than $1 \%$ (Ansmann et al., 1992; Ferrare et al., 1998; Mona et al. 2006). As reported above, the systematic errors on trasmittance due to molecular and ozone terms are on average less than $1 \%$ and $0.5 \%$, respectively. In synthesis, the statistical error on the CLAB is driven by the backscatter coefficient statistical error and therefore is less than $10 \%$, and the systematic error less than $3 \%$.

\section{An example of comparison}

In order to show the capability of PEARL for CALIPSO validation purposes and the comparison methodology, one example of comparison is presented in the following. A major case of Saharan dust intrusion over Europe is considered. Figure 4a reports the vertical profiles of backscatter and extinction measured by PEARL on 13 August 2006, 00:5501:25 UTC. In these profiles, an aerosol layer extending between 2.5 and $5 \mathrm{~km}$ is observed. Lidar ratio and Angstrom exponent mean values calculated in this layer are reported in the same plot as scattered points, and one standard deviation is reported for each one of these mean values as error bars. The observed values are in agreement with those typically observed at CNR-IMAA in occurrences of Saharan dust intrusions. In particular, values of $41 \pm 9 \mathrm{sr}$ and $60 \pm 11 \mathrm{sr}$ are observed for lidar ratios at $355 \mathrm{~nm}$ and $532 \mathrm{~nm}$, respectively. A mean value of $1.2 \pm 0.6$ is obtained for the Angstrom exponent at $532 / 355 \mathrm{~nm}$. The observed values of lidar ratio at $355 \mathrm{~nm}$ and $532 \mathrm{~nm}$ are in perfect agreement with the 3year study on Saharan dust intrusions over Potenza (Mona et al., 2006) and with values of 55-60 sr at $532 \mathrm{~nm}$ observed at CNR-IMAA during a long-range dust transport event (Müller et al., 2009). Moreover, during the same long-range dust transport event, 532/355 nm Angstrom exponent values of 0.5-0.8 have been observed at CNR-IMAA (Müller et al., 2009). This is in good agreement with the hypothesis that the layer observed on 13 August 2006 is related to dust intrusion: the 2 observed values are in agreement within the errors and moreover on 13 August 2006 the Angstrom exponent increases with the altitudes with a value in the middle of the layer of about 0.9 .

NOAA Hysplit back-trajectory analysis (Fig. 4b) shows air masses reaching CNR-IMAA around 3-4 km a.s.l. coming from Southern Spain where on the previous day satellite images show a large amount of dust, supporting the hypothesis about the dust nature of the observed layer.

The procedure reported in the previous section has been applied to retrieve the CALIPSO-like attenuated backscat-

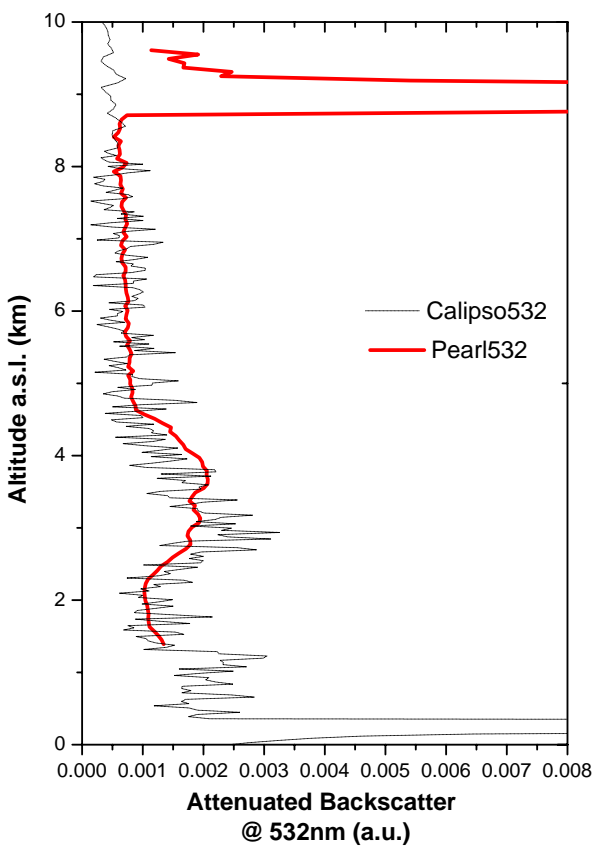

Fig. 5. CALIPSO attenuated backscatter profile at $532 \mathrm{~nm}$ measured at 01:11 UTC on 13 August 2006 and corresponding CALIPSO-like profile calculated from PEARL profiles measured at 00:55-01:25 UTC on 13 August 2006. The reported CALIPSO attenuated backscatter has an horizontal resolution of $5 \mathrm{~km}$, i.e. it is obtained as the average of 15 single shot attenuated backscatter profiles.

ter at $532 \mathrm{~nm}$, from $3+2$ PEARL profiles measured on 13 August 2006, 00:55-01:25 UTC (Fig. 5). It is evident that the CALIPSO vertical profile is highly noisy when compared with the PEARL one. In fact in the CALIPSO algorithms an additional averaging is necessary for the identification of vertical layers reaching also a maximum horizontal averaging of $80 \mathrm{~km}$ (Vaughan et al., 2005). However, the main layering characteristics are evident also in the 5-km horizontal resolution CALIPSO profile reported in Fig. 5 and these are similar to what observed by the ground-based lidar.

Starting from the ground, one can note a sharp spike in the CALIPSO profile that is due to the ground return. There is a sharp decrease around $1.5 \mathrm{~km}$ a.s.l. in the CALIPSO profile, a clear signature of the PBL top, with a residual layer extending up to about $2.5 \mathrm{~km}$, as shown by the almost vertically homogeneous layer observed by the 2 systems. In the free troposphere a wide layer extends between 2.5 and $5 \mathrm{~km}$ a.s.1.. Nevertheless, there are differences in the vertical distribution of the aerosol in the Saharan dust layer. These differences in the free troposphere are to be mainly ascribed to the atmospheric variability that cannot be neglected as demonstrated by the temporal and spatial variations shown in the CALIPSO and PEARL quick-looks reported in Fig. 6a and 6b, respectively, and to the minimum distance of $44.16 \mathrm{~km}$ between CALIPSO ground-track and 

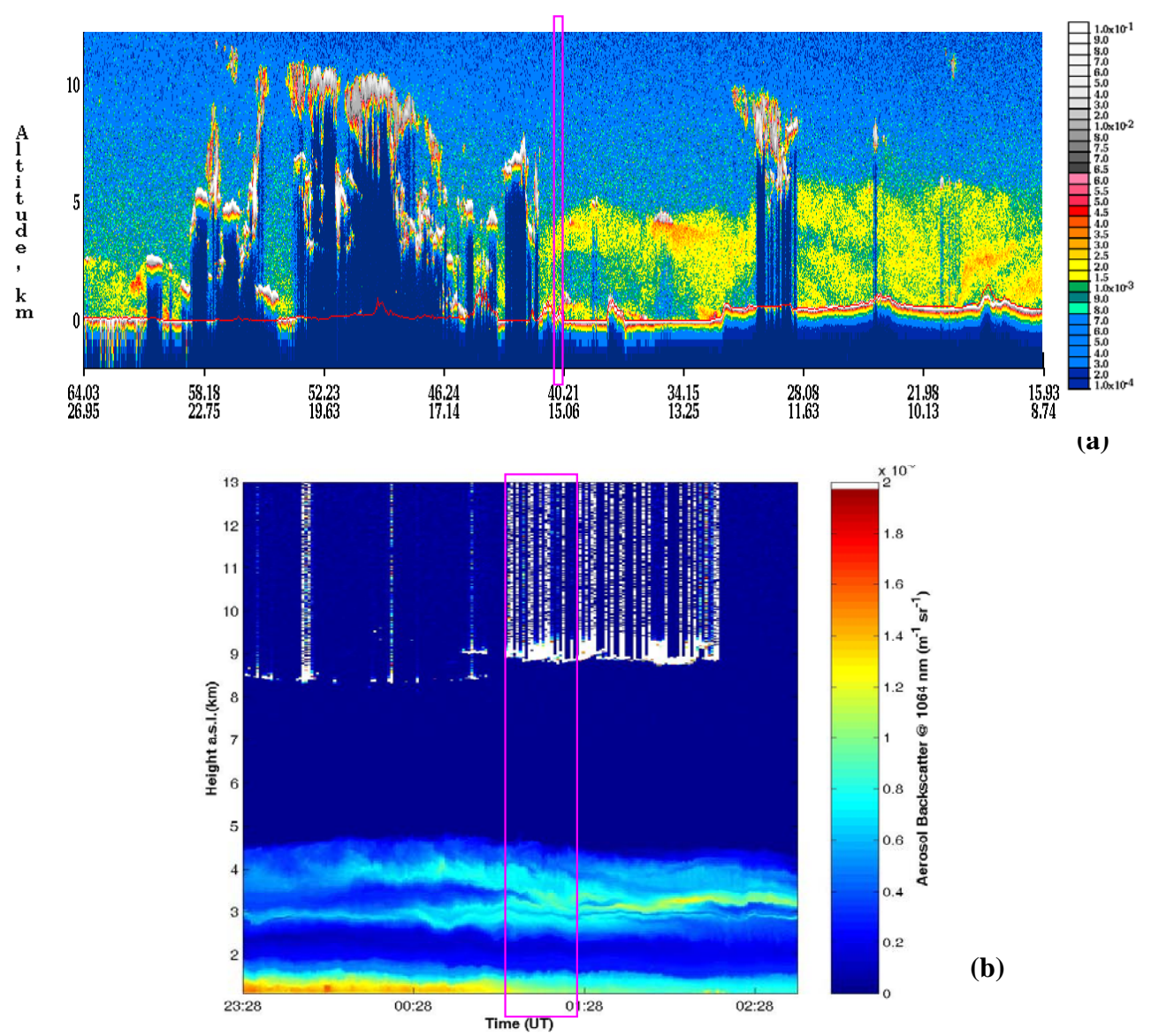

(b)

Fig. 6. (a) Temporal evolution of attenuated backscatter vertical profiles measured by CALIPSO at $532 \mathrm{~nm}$ on 13 August 2006. (b) Temporal evolution of aerosol backscatter coefficient vertical profiles measured at $1064 \mathrm{~nm}$ on 13 August 2006 by PEARL at CNR-IMAA. The vertical and temporal resolution are respectively $7.5 \mathrm{~m}$ and $30 \mathrm{~s}$. The purple box indicates the location in space (a) and time (b) of CALIPSO overpass CNR-IMAA.

CNR-IMAA and the difference in time resolution of the two measurements for the reported case. At this point, it is interesting to note that the layer observed by CALIPSO has been identified as a dust layer by the CALIPSO feature classification algorithm. Finally, a cirrus cloud around $9 \mathrm{~km}$ a.s.l. is evident in PEARL data but it is not observed in CALIPSO measurements. Looking at Figure 6b, it is clear that on this day there was a broken cirrus cloud situation, and CALIPSO did not see cirrus clouds, that were not below CALIPSO orbit because of horizontal distance between the two sensors.

\section{Results}

For a quantitative comparison between ground-based and CALIPSO lidar data in terms of attenuated backscatter, we selected, among all measurements performed at CNRIMAA in correspondence of CALIPSO overpasses, nighttime cases, because, in absence of the solar background, it is possible to obtain independent measurements of vertical pro- files of backscatter and extinction coefficients at $532 \mathrm{~nm}$ and therefore a CALIPSO-like attenuated backscatter profile at the same wavelength using the method reported in Sect. 3.2.

CALIPSO Level 1 data of Version V2.01 are used. Attenuated backscatter profiles are provided in Level 1 data with the original horizontal resolution of $1 / 3 \mathrm{~km}$. In order to reduce the noise in the CALIPSO signal, profiles are averaged on an horizontal scale of $5 \mathrm{~km}$, corresponding to the horizontal resolution of CALIPSO Level 2 Layer Aerosol products (Vaughan et al., 2005). The typical horizontal distance between PEARL and CALIPSO ground-tracks is about $60 \mathrm{~km}$ with a minimum distance of $40.3 \mathrm{~km}$. Profiles are almost coincident in time, because PEARL temporal integration window (typically $30 \mathrm{~min}$ ) is centred around the CALIPSO overpass of Potenza. Following the procedure reported in Sect. 3.2, CLAB is calculated from backscatter and extinction profiles and using ozone profiles embedded in meteorological CALIPSO Level 1 and the molecular profiles calculated from the NOAA modelled radiosounding data. After CLAB calculation, PEARL vertical profiles are reported 


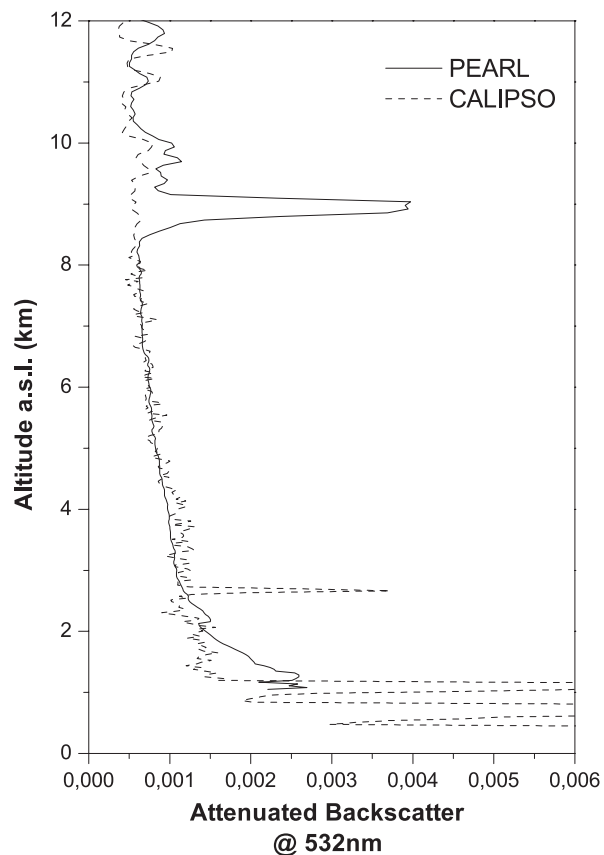

Fig. 7. Mean profiles of attenuated backscatter at $532 \mathrm{~nm}$ as measured by CALIPSO and PEARL for all night-time cases, with no low clouds observed by the CNR-IMAA lidar.

at the same altitudes of CALIPSO vertical profiles through linear interpolation, for allowing a quantitative comparison between the CALIPSO and PEARL datasets.

Low-cloud cases have been identified in PEARL measurements and removed for the comparison reported in this work, because the high variability of low clouds fields and the typical horizontal distance between the 2 sampled air volumes would bias the study.

In this way among the 31 nights when PEARL performed measurements in coincidence with CALIPSO overpasses, we selected 22 cases in absence of low clouds. In 3 cases CALIPSO data are not available and in 3 cases PEARL vertical profiles of particulate extinction are not available. Finally 16 cases are available for the comparison.

Figure 7 reports the mean, over the 16 cases, vertical profiles of attenuated backscatter as measured by CALIPSO and obtained by PEARL data. There is a good agreement between the two observations, even if there are some differences especially in the PBL and at high altitudes where signatures of cirrus clouds are evident. There is a strong peak in CALIPSO data around $2.5 \mathrm{~km}$ a.s.l., signature of very low cloud. The corresponding 2 cases are removed in the analysis reported in the following.

Large differences observed in the PBL region, typically below 2.5 a.s.1. at our station (Pandolfi et al., 2004; Mona et al., 2006), and at low altitudes are probably due to the distance between the location of PEARL and the CALIPSO ground-track that is always larger than $40 \mathrm{~km}$ and to the
CALIPSO horizontal resolution of $5 \mathrm{~km}$. In this context, it is also to be considered that the Potenza lidar station is located at $760 \mathrm{~m}$ a.s.l. with a complex topography of the surrounding area that makes very difficult the comparison in the PBL with satellite data acquired with imperfect spatial coincidence.

The difference between satellite and ground-based observations reaches also $100 \%$ between 8 and $11 \mathrm{~km}$ a.s.l. in the cirrus region, which is not unexpected given the spatial and temporal variability of cirrus and the relatively low number of cases (11) for comparison. A better agreement is achieved in the altitude range between 3 and $8 \mathrm{~km}$, where however it seems that CALIPSO data are higher than ground-based CLAB measurements. These could be an effect of the presence of cirrus cases, with different geometrical and optical properties in the PEARL and CALIPSO observations. Therefore cirrus and no cirrus cases are analysed separately in the following.

\subsection{Cirrus clouds cases}

Among the 14 selected cases, cirrus are observed by PEARL and/or CALIPSO in 5 coincident measurements. However, cirrus are not always detected by both lidars because of the high variability typical of cirrus clouds and of the distance between the air volumes sampled. In particular, cirrus are detected only by PEARL in 2 cases, in just 1 case CALIPSO observes a cirrus cloud not detected by PEARL and finally in 2 cases cirrus clouds are detected by both the ground-based and satellite-borne lidars.

In presence of cirrus clouds, multiple scattering is typically not negligible, in particular for space-borne lidars (Winker, 2003). The main effect of multiple scattering is an apparent extinction and optical depth lower than the real one, with an almost unchanged backscatter. For CALIPSO data, the influence of multiple scattering on Level 1 data has been observed through the comparison with collocated AIRS data (Lamquin et al., 2008) and a multiple scattering correction on Level 2 data is applied for cirrus cloud cases (Liu et al., 2005).

In addition, it is well known that space-borne lidar measurements of ice clouds are typically affected by specular reflection, when observed by lidar pointed near the nadir (Young and Vaughan, 2009). Specular reflection causes anomalously high backscatter, not accompanied by any increase in the extinction (Hogan and Illingworth, 2003). Regarding CALIPSO, at the beginning it was nominally pointed in a "near nadir" direction $\left(\sim 0.3^{\circ}\right.$ off nadir), while after 28 November 2007, it was pointed $3^{\circ}$ off nadir in order to avoid specular reflection effects. Therefore for the time period considered in this study, specular reflection effects cannot be neglected a priori.

Considering these well-known effects for space-borne lidar, here we focus only on cases with cirrus clouds detected by CALIPSO. On the other hand, the 2 cirrus cases observed only by PEARL have been included in the statistics presented 
in the next section after a cirrus cloud removing procedure that rescales the calculated attenuated backscatter taking into account the transmittance terms in the cirrus. For the sake of completeness, here we mention that the results presented in the next section do not change significantly if these 2 cases are not included in the statistics.

Before comparing the CALIPSO and PEARL attenuated backscatter profiles for the 3 CALIPSO observed cirrus cases, these profiles have to be rescaled in order to take into account the difference in transmittance terms due to the presence of cirrus clouds with different geometrical and optical properties in the PEARL and CALIPSO observations.

For ground-based measurements, the cirrus contribution to the transmittance term in (3) is calculated from the extinction profile. A rescaled attenuated backscatter is obtained dividing the old one for evaluated $T^{2}$ term.

For CALIPSO data, cirrus attenuation correction is more complicated because Level 1 data have no information about the extinction profiles and for Level 2 products determination some assumptions are needed. Since we are here interested in a direct comparison with Level 1 data avoiding retrieval assumptions, a method to correct for the cirrus attenuation Level 1 data using only Level 1 products is needed. Following Lamquin et al. (2008), the optical depth and the transmittance term due to the presence of the cirrus are estimated comparing the actual attenuated backscatter profile with Level 1 clear sky profiles acquired close in time and space to the analysed profile. In particular, the closest $50-\mathrm{km}$ clear sky scene within $1000 \mathrm{~km}$ horizontal distance is chosen as the molecular reference. For the cases under investigation, the minimum identified cirrus base height is at about $8 \mathrm{~km}$ a.s.l. At this altitude the aerosol content, and therefore the variations with the distance between the 2 sensors observations, can be considered negligible. The ratio between the actual attenuated backscatter below the cloud and the molecular reference provides transmittance term of the cirrus and therefore the optical depth of the cirrus (Lamquin et al., 2008). Also for the space-borne lidar, the rescaled attenuated backscatter is obtained dividing the old one by the evaluated $T^{2}$ term.

After correcting both PEARL and CALIPSO observations for cirrus attenuation, we can finally compare the new rescaled attenuated backscatter profiles. The mean of attenuated backscatter profiles at $532 \mathrm{~nm}$ as observed by CALIPSO and PEARL in these 3 cirrus clouds cases are reported in Fig. 8a. Profiles are reported only for altitude ranges below the minimum identified cirrus base height.

An almost satisfactory agreement between the 2 profiles is observed in the $6-8 \mathrm{~km}$ a.s.l. altitude range, where a difference of about $(13 \pm 31) \%$ is observed, and in this case, as in the previous comparison, below $2.5 \mathrm{~km}$ a.s.l. there is a large difference of about $(-23 \pm 14) \%$. Larger differences up to $80 \%$ (see Fig. 8) are observed instead in cirrus cases at 3-6 km a.s.l., with a higher attenuated backscatter observed by CALIPSO. The main cause of the observed difference is
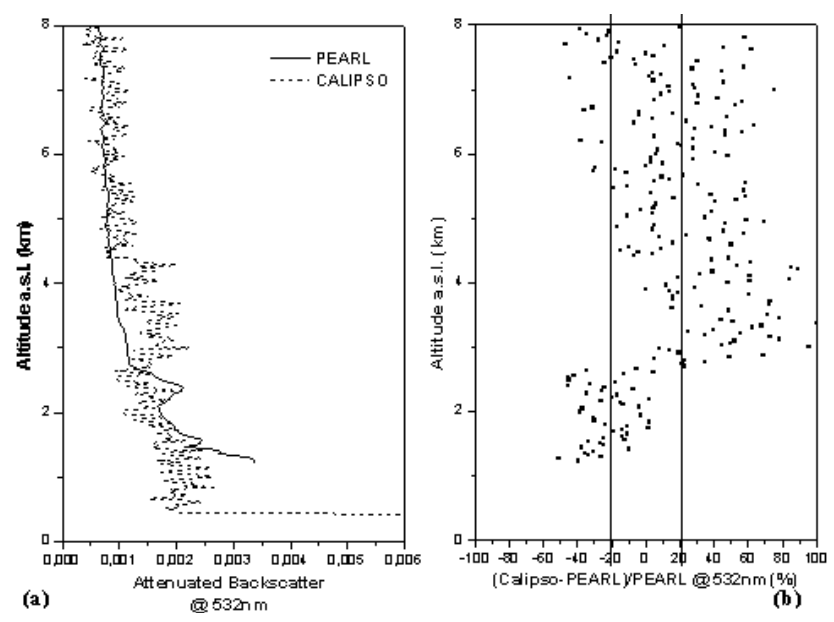

Fig. 8. Comparison between attenuated backscatter at $532 \mathrm{~nm}$ as measured by CALIPSO and PEARL for all night-time cases (3) in which CALIPSO detected cirrus cloud: (a) mean attenuated backscatter profiles and (b) mean percentage difference as a function of the altitude.

related to a single case in which aerosol content is highly variable and CALIPSO detected aerosol up to $5 \mathrm{~km}$, while we observed a Saharan dust layer up to about $3 \mathrm{~km}$, producing the observed large difference. Discarding this case, as mean in the 3-6 km altitude range, a residual difference of $(14 \pm 34) \%$ is obtained, comparable with what obtained in the $6-8 \mathrm{~km}$ range. This could be ascribed to the combination of the aerosol variability at these altitudes and a residual contribution of possible multiple scattering effect that leads to an apparent lower extinction and therefore higher transmittance for the same backscatter, i.e. an apparently increased attenuated backscatter, below the cirrus clouds. On the other hand, specular reflection has to be discarded as the cause of the observed large difference at low altitude, because this effect would lead to an increase of the attenuated backscatter at the altitude where the cirrus cloud is located, but it would not influence the lower portion of the profile.

Due to the low number of cirrus cases comparisons, it is not possible at the moment to draw any conclusions about the presence of multiple scattering effect on CALIPSO signals, but it has to be kept in mind the possibility of nonnegligible effects on the attenuated backscatter in presence of cirrus clouds.

\subsection{Non-cirrus cloud cases}

After removing cirrus cloud cases, a total number of 11 night-time coincident measurements is available for comparison between CALIPSO and PEARL observations. Figure 9 reports, for each case, the CALIPSO attenuated backscatter at $532 \mathrm{~nm}$ (black lines) as reported in Level 1 V2.01 products and averaged on $5 \mathrm{~km}$ as horizontal resolution, and the almost simultaneous PEARL CLAB profiles obtained with 



Attenuated Backscatter @ 532 nm

Fig. 9. CALIPSO attenuated backscatter at $532 \mathrm{~nm}$ (black lines) for all night-time cases of CALIPSO-PEARL correlative measurements in which no cirrus clouds are detected by CALIPSO. The corresponding PEARL CLAB at $532 \mathrm{~nm}$ are reported as red lines. CALIPSO profiles are obtained with $5 \mathrm{~km}$ as horizontal resolution. PEARL profiles are averaged over $30 \mathrm{~min}$ centered on the CALIPSO overpass of CNR-IMAA.

$30 \mathrm{~min}$ as temporal averaging (red lines). These cases range between occurrences of high aerosol load in the free troposphere related to Saharan dust intrusions (e.g. 26 June and 13 August 2006) to very clear conditions (29 January 2007), with a good balance between warm and cold seasons cases.
A very good agreement between CALIPSO and PEARL attenuated backscatter profiles is achieved if only these 11 cases are considered. Compared with Fig. 7, the agreement, for these non-cirrus cases, between the CALIPSO and PEARL attenuated backscatter mean profiles (Fig. 10a) is improved at all altitude ranges apart from the very low 


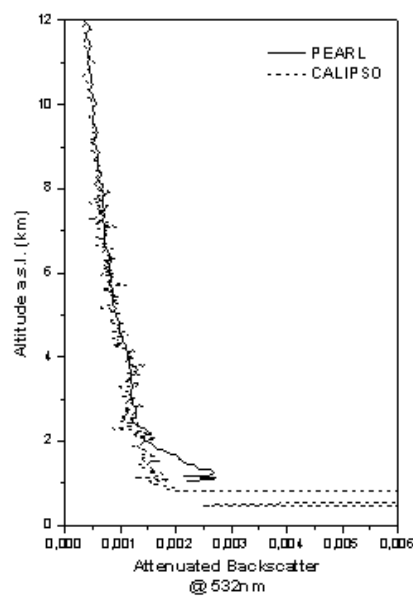

(a)

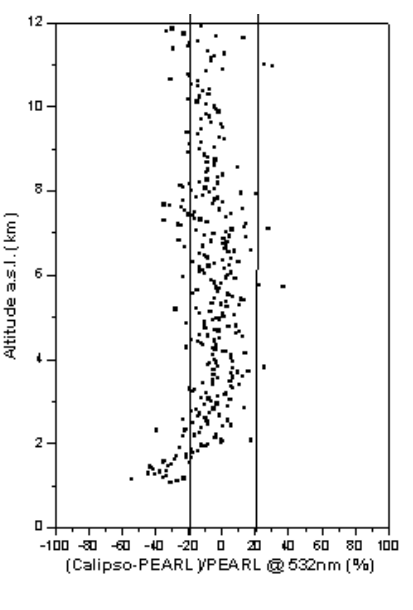

(b)

Fig. 10. Comparison between attenuated backscatter at $532 \mathrm{~nm}$ as measured by CALIPSO and PEARL for all night-time cases in which no cirrus clouds are detected by CALIPSO: (a) mean attenuated backscatter profiles and (b) mean percentage difference as a function of the altitude.

atmosphere below $2.5 \mathrm{~km}$ a.s.l., identified as the typical boundary layer top at CNR-IMAA (Pandolfi et al., 2004; Mona et al., 2006). In particular, differences are strongly reduced not only in the altitude range occupied by the cirrus cloud ( $8-12 \mathrm{~km}$ a.s.1.), but also in the middle range down to $2.5 \mathrm{~km}$ a.s.1.. The observed difference in attenuated backscatter reported in Fig. 7 at the middle altitude range is significantly reduced when cirrus cloud cases are removed from the statistical analysis.

Figure $10 \mathrm{~b}$ reports the relative difference of mean CALIPSO attenuated backscatter profiles at $532 \mathrm{~nm}$ with respect to the corresponding quantity measured by PEARL. Above the lowest $2.5 \mathrm{~km}$ a.s.l., differences are typically within $20 \%$, which is the expected error of Level 2 CALIPSO vertical profiles (Winker et al., 2004).

The mean difference of the whole mean profile is around $-12 \%$ with a standard deviation of about $28 \%$. Even if this value is in agreement with zero within the error, it is largely shifted toward negative values. In order to better investigate the reason of this negative difference, the CALIPSO vs PEARL difference in the attenuated backscatter is investigated as a function of the altitude range (Fig. 11) and of the CALIPSO-PEARL horizontal distance (Fig. 12).

Figure 11 reports the mean relative difference between CALIPSO and PEARL observations for different atmospheric layers calculated as average on the 11 considered cases. The related standard deviations are reported as error bars. The analysis is reported up to $8 \mathrm{~km}$, where the PEARL statistical error is lower than $10 \%$. At higher altitudes, it has to be considered that besides the large ground-based measurements statistical errors, the molecular terms of Eq. (1) strongly influence the CLAB calculation in this free aerosol

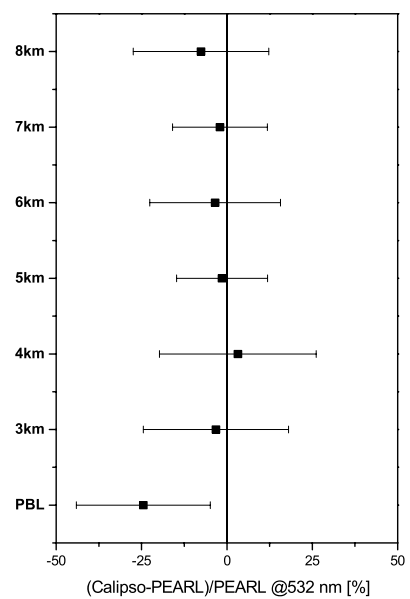

Fig. 11. Mean percentage difference between CALIPSO and PEARL attenuated backscatter at 532 calculated for the PBL region and for the $1 \mathrm{~km}$-depth altitude layers extending between $3-8 \mathrm{~km}$ for all non-cirrus night-time cases. The standard deviations around these mean values are reported as error bars.

region. For these reasons, in the following we limit the comparison to the altitude range below $8 \mathrm{~km}$.

Looking at Fig. 11, it is clear that the negative difference obtained on the whole profile is mainly due to the PBL region, typically below $2.5 \mathrm{~km}$ a.s.l., where a relative difference of $(-24 \pm 20) \%$ is observed. As reported above, the comparison at PBL altitudes is not appropriate due to the distance, always larger than $40 \mathrm{~km}$, between CALIPSO groundtracks and the CNR-IMAA. Because of the distance and because of the local aerosol content at this altitude range, one could expect an imperfect agreement between the two observations for case-by-case comparison. However, if there are no systematic differences between the scenario observed by PEARL and CALIPSO, one could expect that a large number of observations would result in a mean difference in the PBL close to zero, and because of the large variability at these altitudes, in a large standard deviation around this mean value. This is not the case: CALIPSO sees a smaller aerosol content in this low altitude region. This could be linked to the difference between the location of PEARL and the exact location of the CALIPSO ground-track. For the typical CALIPSO ground-tracks in the Potenza surroundings for night-time overpasses (see Fig. 1), the closest point to CNRIMAA is located closer than Potenza to the sea and at a lower altitude. Taking into account that Potenza is not an uncontaminated mountain site, but a city with an industrial area surrounded by rural areas located at $760 \mathrm{~m}$ a.s.l., this could lead to a PBL top height higher over Potenza rather than over CALIPSO ground-track closest points, and as a consequence, to a higher aerosol load (both extinction and backscatter, i.e. attenuated backscatter) in the altitude range corresponding to PBL for a mountain site rather than for other locations. 


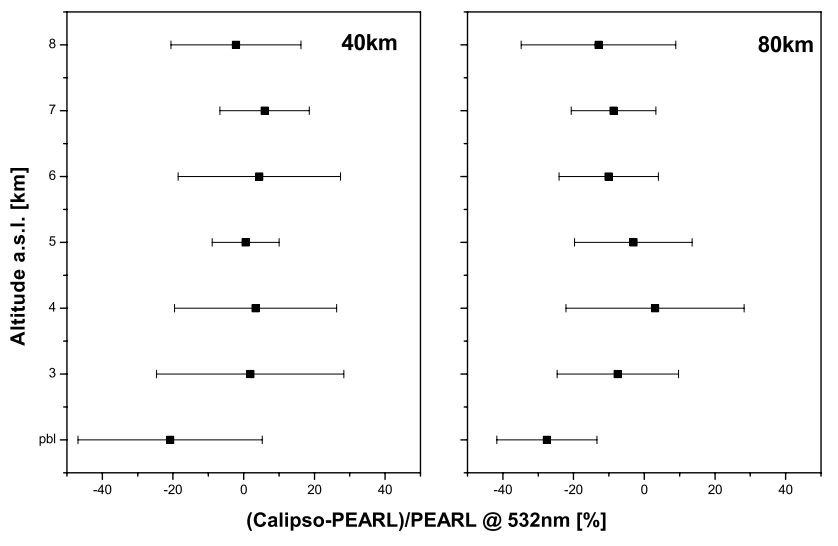

Fig. 12. Mean percentage difference between CALIPSO and PEARL attenuated backscatter at 532 for non-cirrus night-time cases divided into two classes: overpasses at about $40 \mathrm{~km}$ (left panel) and at about $80 \mathrm{~km}$ (right panel). The standard deviations around these mean values are reported as error bars.

At higher altitudes, CALIPSO vs PEARL differences are typically slightly negative although the two independent observations are always in agreement within their standard deviations.

Between 3 and $8 \mathrm{~km}$, the 1-km mean differences are very close to zero and range between -7.5 and $3.6 \%$ with a typical standard deviation of $18 \%$. At these altitudes, the mean percentage difference between the ground-based and CALIPSO measured attenuated backscatter (Fig. 10b) is $(-2 \pm 12) \%$. This very small residual difference, in agreement with zero, could be due to the CALIPSO calibration procedure, however, because of the large standard deviation, no conclusions can be drawn about this point. The observed large standard deviations can be ascribed to the horizontal distance between the volumes sampled by the 2 lidars in conjunction with the variability of the aerosol field at these altitudes where the wind is responsible of fast changes both in time and space (see for example Fig. 6a and b).

In order to further investigate the relationship between the observed differences and the spatial variability in the aerosol field, the difference between CALIPSO and PEARL attenuated backscatter at $532 \mathrm{~nm}$ is studied as a function of the horizontal distance between the two sensors. There are two groups of overpasses, one with closest distance around $43 \mathrm{~km}$ (5 cases) and a more-distant overpass around $83 \mathrm{~km}$ (6 cases), corresponding to the 2 typical ground-tracks reported in Fig. 1. The closest overpass is located at NorthWest of Potenza, between the Appennines and the Salerno Gulf, while the overpass at about $80 \mathrm{~km}$ from Potenza is much closer to the sea, pretty close to a coastal and flat region, the Ionian Sea region.

The mean percentage relative difference between CALIPSO and PEARL attenuated backscatter at $532 \mathrm{~nm}$ is reported in Fig. 12 for each one of these 2 overpasses classes for the different atmospheric layers. Also in these cases the standard deviation of the observed values is reported as error bars. Although in agreement with the standard deviation, the mean differences are lower when the closest overpasses are considered, with an increment of the differences at all altitude ranges when the $80 \mathrm{~km}$ overpasses are considered. For both 40 and $80 \mathrm{~km}$ distances, larger standard deviations are observed typically in the lower atmospheric altitude layers because of the large variability of the aerosol field at these altitudes. For both classes the mean difference observed in the PBL (namely below $2.5 \mathrm{~km}$ a.s.l., the typical PBL height as measured at CNR-IMAA) is significantly negative, with lowest values observed for the $80 \mathrm{~km}$ overpasses. This furthermore supports our hypothesis that the negative differences observed in the PBL are strongly affected by the differences between a mountain but polluted site like Potenza, and the Potenza closest ground-track point observed by CALIPSO. In fact, the mean differences in the PBL are larger, in absolute values, when overpasses much closer to the sea are considered.

\section{Conclusions and perspectives}

Since June 2006, devoted measurements are performed at CNR-IMAA EARLINET station in coincidence with CALIPSO overpasses. The $3+2$ capability of PEARL aerosol lidar makes this ground-based station a reference point for the assessment of uncertainty of CALIPSO products as well as for the improvement of CALIPSO retrieval algorithm. In this paper, first results on one year of night-time coincident measurements are reported. In particular, comparison between the satellite-borne and ground-based lidar measurements is carried out in terms of Level 1 data for the June 2006-June 2007 period. Only after a detailed check of Level 1 data (which are, except for a constant, unprocessed data), the comparison in terms of CALIPSO Level 2 data (i.e. backscatter profiles) will allow us to check and improve CALIPSO retrieval algorithms and assumptions.

A methodology for comparing ground-based Raman measurements and CALIPSO Level 1 data is described in detail. In particular, assumptions regarding the molecular profile and the related uncertainty are discussed and quantified. For a statistical analysis, cirrus cloud cases and clear sky cases have been analysed separately.

Cases with cirrus clouds are identified and treated properly: cases of cirrus observed only by ground-based lidar are rescaled with the measured cirrus transmittance and included in non-cirrus cases statistics, cases with cirrus detected by satellite-borne lidar are rescaled and compared to the corresponding ground-based lidar data. For these cases, a satisfactory agreement is obtained, with a mean difference of $(14 \pm 34) \%$ in the middle altitude range $(3-6 \mathrm{~km})$, larger differences are obtained in the rest of the profile. However, because of the very low number of cirrus cloud cases (3), it is 
not possible to draw at the moment any conclusions about the reason of the observed differences.

For the clear sky cases, a good agreement is obtained on average at all investigated altitudes (PBL up to $12 \mathrm{~km}$ a.s.l.). Apart from the PBL region, the mean difference between the ground-based and CALIPSO measured attenuated backscatter is always within one standard deviation at all altitudes, with a mean difference in the $3-8 \mathrm{~km}$ altitude range of $(-2 \pm 12) \%$. Widely scattered values in the observed differences and the resulting large standard deviation of the mean difference values are the results of the atmospheric variability at the investigated altitudes. In the PBL region, attenuated backscatter measured by CALIPSO is typically smaller than the corresponding one obtained by PEARL profiles, because the 2 sampled volumes are more distant than $40 \mathrm{~km}$ and very different in nature: mountain region with industrial and rural area for PEARL and low altitude and coastal region for CALIPSO.

The study of the differences between satellite-borne and ground-based lidar also as a function of the horizontal distance of the sampled volumes has shown that at all altitudes differences are smaller for closer overpasses.

On the basis of these satisfactory results on CALIPSO Level 1 quality, a devoted study for the accuracy of CALIPSO aerosol backscatter profiles will be carried out for evaluation and improving of the retrieval algorithms. On the other hand, in order to better address still unclear points, such as the possible influence of CALIOP geometry on the PBL and to validate CALIPSO data on continental scale, profiles provided by all EARLINET stations will be used in synergy applying the methodology presented in this paper, taking also advantage of other studies performed within the network (e.g. Mattis et al., 2007; Mattis et al., 2008; Mamouri et al., 2009). Finally after a quality check of CALIPSO Level 1 products, an integrated study of CALIPSO and EARLINET correlative measurements will open new possibilities for spatial (both horizontal and vertical) and temporal variability of aerosol and clouds investigations.

Acknowledgements. The financial support for EARLINET by the European Commission under grant RICA-025991 is gratefully acknowledged. We acknowledge the support of the European Commission through GEOmon Integrated Project under the 6th Framework Programme (contract number FP6-2005-Global-4-036677).

CALIPSO data were obtained from the NASA Langley Research Center Atmospheric Science Data Center. The authors also thank to the CALIPSO QPQ team of the NASA Langley Research Center for the provision of the CALIPSO ground track data. The atmosphere meteorological products are provided by NOAA through (REAL) Real-time Environmental Applications and Display system. We also thank the NOAA Air Resources Laboratory (ARL) for the provision of the HYSPLIT backtrajectory analysis.

Finally, the authors want to express their thanks to Mark Vaughan for his invaluable suggestions.

Edited by: J. Quaas

\section{References}

Amodeo, A., Mattis, I., Böckmann, C., et al.: A European research infrastructure for the aerosol study on a continental scale: EARLINET-ASOS, Remote Sensing of Clouds and the Atmosphere XII, edited by: Comerón, A., Picard, R. H., Schäfer, K., Slusser, J. R., and Amodeo, A., Proc. SPIE Vol. 6745, 67450Y, 0277-786X/07/18,doi:10.1117/12.738401, 2007.

Anderson, T. L., Masonis, S. J., Covert, D. S., Ahlquist, N. C., Howell, S. G., Clarke, A. D., and McNaughton, C. S.: Variability of aerosol optical properties derived from in situ aircraft measurements during ACE-Asia, J. Geophys. Res., 108, 8647, doi:10.1029/2002JD003247, 2003.

Ansmann, A., Riebesell, M., and Weitkamp, C.: Measurement of atmospheric aerosol extinction profiles with a Raman lidar, Opt. Lett., 15, 746-748, 1990.

Ansmann, A., Riebesell, M., Wandinger, U., Weitkamp, C., Voss, E., Lahmann, W., and Michaelis, W.: Combined Raman elasticbackscatter lidar for vertical profiling of moisture, aerosol extinction, backscatter and lidar ratio, Appl. Phys. B., 55, 18-28, 1992.

Ansmann A., Wandinger, U., Riebesell, M., Wietkamp, C., and Michaelis, W.: Independent measurements of extinction and backscatter profiles in cirrus clouds by using a combined Raman elastic-backscatter lidar, Appl. Opt., 31(33), 7113-7131, 1992b.

Böckmann, C., Wandinger, U., Ansmann, A., et al.: Aerosol lidar intercomparison in the framework of the EARLINET project 2 Aerosol backscatter algorithms, Appl. Opt., 43(4), 977-989, 2004.

Bösenberg, J. and Matthias, V.: EARLINET: A European Aerosol Research Lidar Network to Establish an Aerosol Climatology, Max-Planck-Institut für Meteorologie, Report No. 348, Hamburg, Germany, September 2003.

Brasseur, G. and Solomon, S.: Aeronomy of the Middle Atmosphere, D. Reidel Publishing, Dordrecht, The Netherlands, 156, 1985.

Bucholtz, A.: Rayleigh-scattering calculations for the terrestrial atmosphere, Appl. Opt., 34(15), 2765-2773, 1995.

Cattrall, C., Reagan, J., Thome, K., and Dubovik, O.: Variability of aerosol and spectral lidar and backscatter and extinction ratios of key aerosol types derived from selected Aerosol Robotic Network locations, J. Geophys. Res., 110, D10S11, doi:10.1029/2004JD005124, 2005.

Di Girolamo, P., Ambrico, P. F., Amodeo, A., Boselli, A., Pappalardo, G., and Spinelli, N.: Aerosol observations by lidar in the nocturnal boundary layer, Appl. Opt., 38(21), 4585-4595, 1999.

Diner, D. J., Ackerman, T., Anderson, T. L., et al.: PARAGON: An Integrated Approach for Characterizing Aerosol Climate Impacts and Environmental Interactions, B. Am. Meteor. Soc., 85(10), doi:10.1175/BAMS-85-10-1491, 1491-1501, 2004.

Ferrare, R. A., Melfi, S. H., Whiteman, D. N., Evans, K. D., Poellot, M., and Kaufman, Y. J.: Raman lidar measurements of aerosol extinction and backscattering 2. Derivation of aerosol real refractive index, single-scattering albedo, and humidification factor using Raman lidar and aircraft size distribution measurements, J. Geophys. Res., 103(D16), 19673-19689 1998.

Forster, P., Ramaswamy, V., Artaxo, P., et al. in Climate Change 2007: The Physical Science Basis, Contribution of Working Group I to the Fourth Assessment Report of the Intergovernmen- 
tal Panel on Climate Change, edited by: Solomon, S., Qin, D., Manning, M., Chen, Z., Marquis, M., Averyt, K. B., Tignor, M., and Miller, H. L., Cambridge Univ. Press, New York, USA, online available at: http://www.ipcc.ch, 2007.

Hair, J. W., Hostetler, C. A., Cook, A. L., Harper, D. B., Ferrare, R. A., Mack, T. L., Welch, W., Izquierdo, L. R., and Hovis, F. E.: Airborne High Spectral Resolution Lidar for Profiling Aerosol Optical Properties, Appl. Opt., 47, 6734-6752, doi:10.1364/AO.47.006734, 2008.

Hogan, R. J. and Illingworth, A. J.: The effect of specular reflection on spaceborne lidar measurements of ice clouds, Report of the ESA Retrieval algorithm for EarthCARE project, 2003.

Hostetler, C. A., Liu, Z., Reagan, J., Vaughan, M., Winker, D., Osborn, M., Hunt, W. H., Powell, K. A., and Trepte, C.: Calibration and level 1 data products, in CALIOP algorithm theoretical basis document, NASA Langley Research Center, Hampton, Virginia, USA, April 2006.

$\mathrm{Hu}$, Y., Vaughan, M., McClain, C., Behrenfeld, M., Maring, H., Anderson, D., Sun-Mack, S., Flittner, D., Huang, J., Wielicki, B., Minnis, P., Weimer, C., Trepte, C., and Kuehn, R.: : Global statistics of liquid water content and effective number concentration of water clouds over ocean derived from combined CALIPSO and MODIS measurements, Atmos. Chem. Phys., 7, 3353-3359, 2007,

http://www.atmos-chem-phys.net/7/3353/2007/.

Kahn, R. A., Garay, M. J., Nelson, D. L., Yau, K. K., Bull, M. A., Gaitley, B. J., Martonchik, J. V., and Levy, R. C.: Satellite-derived aerosol optical depth over dark water from MISR and MODIS: Comparison with AERONET and implication for climatological studies, J. Geophys. Res., 112, D18205, doi:10.1029/2006JD008175, 2007.

Kaufman, Y. F., Holben, B. N., Tanré, D., Slutsker, I., Smirnov, A., and Eck, T. F.: Will aerosol measurements from Terra and Aqua polar orbiting satellites represent the daily aerosol abundance and properties?, Geophys. Res. Lett., 27, 3861-3864, 2000.

Lamquin, N., Stubernrauch, C. J., and Pelon, J.: Upper tropospheric humidity and cirrus geometrical and optical thickness : Relationships inferred from 1 year of collocated AIRS and CALIPSO data, J. Geophys. Res., 113, D00A08, doi:10.1029/2008JD010012, 2008.

Liu, Z., Omar, A. H., Hu, Y., Vaughan, M. A., and Winker, D. M.: CALIOP Algorithm Theoretical Basis Document, Part 3: Scene Classification Algorithms, Tech. rep., online available at: http://www-calipso.larc.nasa.gov/resources/ projectdocumentation.php, 2005.

Mamouri, R. E., Amiridis, V., Papayannis, A., Giannakaki, E., Tsaknakis, G., and Balis, D. S.: Validation of CALIPSO spaceborne-derived aerosol vertical structures using a ground-based lidar in Athens, Greece, Atmos. Meas. Tech. Discuss., 2, 561587, 2009,

http://www.atmos-meas-tech-discuss.net/2/561/2009/.

Matthias, V., Bösenberg, J., Freudenthaler, V., et al.: Aerosol lidar intercomparison in the framework of the EARLINET project. 1 Instruments, Appl. Opt., 43(4), 961-976, 2004.

Mattis I., Mona, L., Müller, D., et al.: EARLINET correlative measurements for CALIPSO, Lidar Technologies, Techniques, and Measurements for Atmospheric Remote Sensing III, edited by Upendra N. Singh, Gelsomina Pappalardo, Proc. SPIE, 6750, 67500Z, doi:10.1117/12.7380902007, 2007.
Mattis, I., Müller, D., Baars, H., et al. : Complementary use of EARLINET, CALIPSO and AERONET observations: case study July 24, 2006, Reviewed and revised papers presented at the 24th ILRC, 23-27 July 2008 Boulder, Colorado, 2, 1121-1124, 2008.

Mona, L., Amodeo, A., Pandolfi, M., and Pappalardo, G.: Saharan dust intrusions in the Mediterranean area: three years of Raman lidar measurements, J. Geophys. Res., 111, D16203, doi:10.1029/2005JD006569, 2006.

Müller, D., Ansmann, A., Mattis, I., Tesche, M., Wandinger, U., Althausen, D. and Pisani, G.: Aerosol-type-dependent lidar ratios observed within Raman lidar, J. Geophys. Res., 112, D16202, doi:10.1029/2006JD008292, 2007.

Müller, D., Heinold, B., Tesche, M., et al.: EARLINET Observations of the 14-22-May Long-Range Dust Transport Event During SAMUM 2006: Validation of Results From Dust Transport Modelling, Tellus, 61B, 325-339, 2009.

Omar, A. H., Won, J.-G., Winker, D. M., Yoon, S.-C., Dubovik, O., and McCormick, M. P.: Development of global aerosol models using cluster analysis of Aerosol Robotic Network (AERONET) measurements, J. Geophys. Res., 110, D10S14, doi:10.1029/2004JD004874, 2005.

Papayannis, A., Amiridis, V., Mona, L., et al.: Systematic lidar observations of Saharan dust over Europe in the frame of EARLINET (2000-2002), J. Geophys. Res., 113, D10204, doi:10.1029/2007JD009028, 2008.

Pandolfi, M., Amodeo, A., Cornacchia, C., Mona, L., and Pappalardo, G.: Three years of Raman lidar measurements of tropospheric aerosol over Potenza in the framework of EARLINET, 22nd ILRC, 12-16 July 2004 Matera, Italy, Edited by: Pappalardo, G. and Amodeo, A., SP-561, 2, 853-856, 2004.

Pappalardo, G., Amodeo, A., Pandolfi, M., et al.: Aerosol lidar intercomparison in the framework of the EARLINET project. 3 -Raman lidar algorithm for aerosol extinction, backscatter and lidar ratio, Appl. Opt., 43(28), 5370-5385, 2004.

Sassen K., Wang, Z., and Liu, D.: Global distribution of cirrus clouds from CloudSat/Cloud-Aerosol Lidar and Infrared Pathfinder Satellite Observations (CALIPSO) measurements, J. Geophys. Res., 113, D00A12, doi:10.1029/2008JD009972, 2008.

Stephens, G. L., Vane, D. G., Boain, R. J., et al.: The CloudSat mission and the A-Train: a new dimension of space-based observations of clouds and precipitation, B. Am. Meteor. Soc., 83, 1771-1790, 2002.

US Standard Atmosphere, US Government Printing Office, Washington, DC, USA, 241 pp., 1976.

Vaughan, M. A., Winker, D. M., and Powell, K. A.: CALIOP Algorithm Theoretical Basis Document, Part 2: Feature Detection and Layer Properties Algorithm, Tech. rep., online available at: http://wwwcalipso.larc.nasa.gov/resources/ projectdocumentation.php, 2005.

Wandinger, U. and Ansmann, A.: Experimental determination of the lidar overlap profile with Raman lidar, Appl. Opt., 41, 511514, 2002.

Winker, D.: Accounting for multiple scattering in retrievals from space lidar, Proc. SPIE Int. Soc. Opt. Eng., 5059, 128-139, 2003.

Winker, D., Trepte, C., Pelon, J., Garnier, A., and Kovacs, T.: CALIOP Science Validation Plan, Tech. rep., online available at: http://calipsovalidation.hamptonu.edu/missionplan.htm, 2004

Winker, D. M., Hunt, W. H., and McGill, M. J.: Initial perfor- 
mance assessment of CALIOP, Geophys. Res. Lett., 34, L19803, doi:10.1029/2007GL030135, 2007.

Young, S. A., Winker, D. M., Vaughan, M. A., Hu, Y., and Kuehn, R. E.: CALIOP Algorithm Theoretical Basis Document, Part 4: Extinction Retrieval Algorithms, Tech. rep., online available at: http://wwwcalipso.larc.nasa.gov/resources/ projectdocumentation.php, 2008.
Young, S. A. and Vaughan, M. A.: The Retrieval of Profiles of Particulate Extinction from Cloud-Aerosol Lidar Infrared Pathfinder Satellite Observations (CALIPSO) Data: Algorithm Description. J. Atmos. Oceanic Technol., 26(6), 1105-1119, 2009. 